Review

\title{
Construction Planning and Operation of Battery Swapping Stations for Electric Vehicles: A Literature Review
}

Yu Feng and Xiaochun Lu *(D)

School of Economics and Management, Beijing Jiaotong University, Beijing 100044, China; 19113037@bjtu.edu.cn

* Correspondence: xclu@bjtu.edu.cn

\begin{abstract}
The popularity of electric vehicles has been limited by factors such as range, long charging times and fast power failure in winter. In order to overcome these challenges, battery swapping stations (BSS) have been constructed and greatly promoted in recent years. In this paper, the related literature on electric vehicle service is reviewed and the co-occurrence of keywords is analyzed using CiteSpace. The literature is classified according to clustering results and recurring themes, such as the location of BSS, inventory decisions, charging strategies and BSS assignment. In each topic, typical optimization models and algorithms proposed in previous studies are summarized. Then, this paper gives a case about the business model and revenue capacity calculation of BSS. Finally, it points out the future research direction of battery swapping stations for electric vehicles.
\end{abstract}

Keywords: electric vehicle; battery swapping station; location problem; battery inventory; charging strategy; BSS assignment

\section{Introduction}

At present, fuel oil is still the main power source for land transportation, aviation and Construction Planning and Operation of Battery Swapping Stations for Electric Vehicles: A Literature Review. Energies 2021, 14, 8202. https:// doi.org $/ 10.3390 /$ en14248202

Academic Editor: Katarzyna Antosz

Received: 10 November 2021

Accepted: 1 December 2021

Published: 7 December 2021

Publisher's Note: MDPI stays neutral with regard to jurisdictional claims in published maps and institutional affiliations. navigation, and the high demand for fuel oil will also bring a lot of carbon emissions, so the transportation industry has become the second largest source of carbon emissions in the world [1]. Faced with the threat brought by the rapid increase in carbon emissions and oil demand, countries around the world have taken measures such as legislation and policy oaths to carry out emission reduction actions. Sustainable transportation has also been proposed [2,3], and electric vehicles are considered as the most promising sustainable transportation route. The electric vehicle is a vehicle that runs on electricity alone. Unlike conventional vehicles that only use fossil fuels, e-vehicles employ an electric motor to run the wheels. According to a report released by the International Energy Agency, the 2010s were ground breaking for the introduction of electric vehicles toward shaping a promising nascent market [4]. There were only approximately 17,000 electric cars on road globally in 2010. By the end of 2020, there were 11.3 million, including 5.4 million in China, 3.3 million in Europe and 1.8 million in the United States [4]. With the support of government policies and promotion strategies of car companies, the penetration rate of electric vehicles in the world will further increase.

Advantages of using an electric vehicle:

- Less air pollution.

- Less noise pollution.

- Low fuel and operating cost.

However, the limitations of electric cars are:

- High price. Electric car production is not yet fully commercialized. Hence, these vehicles are more expensive than conventional cars that run on petrol or diesel.

- Low-range EVs can travel less than half the distance of gas-powered vehicles before they require a "fill-up". 
EVs have to overcome the lack of range, long charging times, and the lack of infrastructure before consumers will be willing to buy them [5]. To realize the large-scale popularization of electric vehicles, mature battery technology and the construction of basic charging facilities are key [6].

\subsection{Current Bottleneck in Charging Mode}

In order to solve this dilemma, the government has invested a lot of energy in infrastructure deployment. Service operation of electric vehicle charging stations has become a hot issue for scholars; for example, the deployment of charging stations [7-9], electric vehicle interaction with power systems [10-12] and the VRP problem with charging stations [13-18]. However, as the main mode of energy supply for electric vehicles, charging mode also has two main problems that restrict the industrialization of electric vehicles. First, charging time is long and charging is inconvenient. Table 1 shows the current charging mode of electric vehicles. AC charging pile is small in size and convenient to install, which is suitable for slow charging, but the charging time is long, $6 \sim 10 \mathrm{~h}$. DC charging can greatly shorten the charging time, but the strong current has a great impact on the power grid and on battery life. Second, whether employing fast charging or slow charging, when a large number of electric vehicles are charged in disorder, this will have an impact on the power grid. At the same time, when car owners choose a charging place and time, they are usually random. Although orderly charging under the time-of-use price can cut peaks and fill valleys, it is difficult to guide users to take the initiative in reality. Therefore, the battery swapping mode is an effective way to quickly replenish energy [19].

Table 1. EV charging mode comparisons.

\begin{tabular}{ccc}
\hline Charging Mode & Slow Charging & Fast Charging \\
\hline Charging equipment & AC charging pile+ & DC charging pile+ \\
Charging duration & on-board charger & DC charger \\
Infrastructure cost & $6-10 \mathrm{~h}$ & 30 min-2 h \\
Impact on battery life & low & high \\
\hline
\end{tabular}

\subsection{Advantages and Problems of Battery Swapping Stations}

Battery swapping, as an alternative refueling option realized through battery swapping stations (BSS), is being considered [20]. Figure 1 shows the structure of BSS. It refers to the rapid recovery of electric vehicle energy by replacing batteries when the electric vehicle energy is about to run out. Electric vehicle users only own cars and rent batteries from service operators, thus greatly reducing the purchase cost of electric vehicles and solving the problem of long charging times. In 2011, Israel's Better Place first promoted battery swapping in Denmark, then signed agreements on the development of electric vehicles in Australia, Tokyo and Canada, reaching the intention of building battery swapping stations. Tesla, an American electric vehicle giant, also launched a pilot project for replacing electric vehicles [19,21], and Gogoro, an electric motorcycle from Taiwan Province, also completed the layout of the electric motorcycle replacement network in Taipei. Although Better Place was finally declared bankrupt due to the break of capital chain, and Tesla's pilot project of power conversion did not continue to be implemented, the concept of battery swapping has attracted attention in China. In 2014, BAIC Group indicated that it would vigorously promote the construction of battery swapping stations in the Yangtze River Delta and Pearl River Delta regions; and in 2015, it will jointly build battery swapping stations with Sinopec. In 2018, Weilai Company's battery swapping station for private users was built in Shenzhen. With the continuous expansion of electric vehicle market, many enterprises such as Aodong New Energy, Sinopec, and Weilai accelerated the layout of power stations, which shows that the technological path of battery swapping is an important direction for the development of the new energy automobile industry. Table 2 compares the techniques for battery swapping and battery charging. 


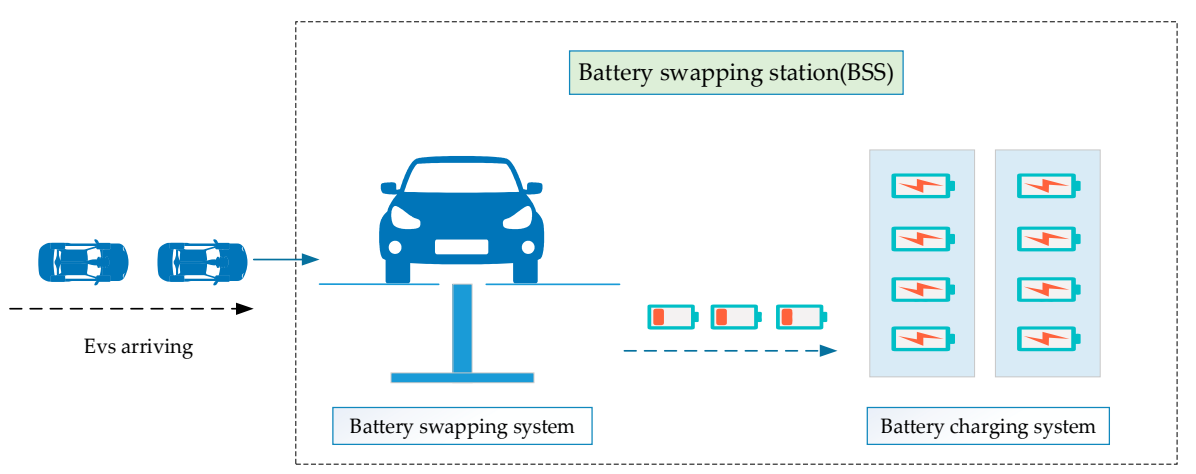

Figure 1. BSS architecture.

Table 2. EVs battery swapping technology vs. charging technology.

\begin{tabular}{|c|c|c|}
\hline & Battery Swapping & Charging \\
\hline Charging efficiency & $3-5 \mathrm{~min}$ & $\geq 30 \mathrm{~min}$ \\
\hline Battery recycling & easy battery recovery & difficult battery recovery \\
\hline Battery maintenance & $\begin{array}{l}\text { managed by professionals, } \\
\text { extending the battery life by } 30-60 \%\end{array}$ & $\begin{array}{c}\text { managed by consumer, short } \\
\text { battery life }\end{array}$ \\
\hline Operability & Manual charging & Intelligent, fully automated \\
\hline
\end{tabular}

Figure 2 shows the operating framework of a battery swapping station. It can be seen that it is a system in which users, battery swapping stations and power grids interact with each other. When the EV battery reaches the threshold of changing power, a BSS will be selected to change power and generate depleted batteries (DB) to be recharged, then put the battery to be charged into chargers. EVs must wait if there are no fully charged batteries (FB) in the station. It can be seen that the battery swapping station is not a separate operation system. Due to the operation of battery charging or discharging, the battery, the distribution network and the battery swapping station are all under centralized management and constitute an integrated system. Compared with the charging station, the battery swapping station (BSS) has three main advantages:

- Reducing the initial purchase cost for consumers. Since batteries account for $40 \%$ of the total cost of vehicles, consumers do not need to pay high battery costs under the concept of vehicle battery separation.

- Quickly replenishing energy. It only takes approximately 3-5 min.

- $\quad$ Reducing the load on the power grid. It is easier to manage the battery in a unified way and play an active role in controlling the charging load.

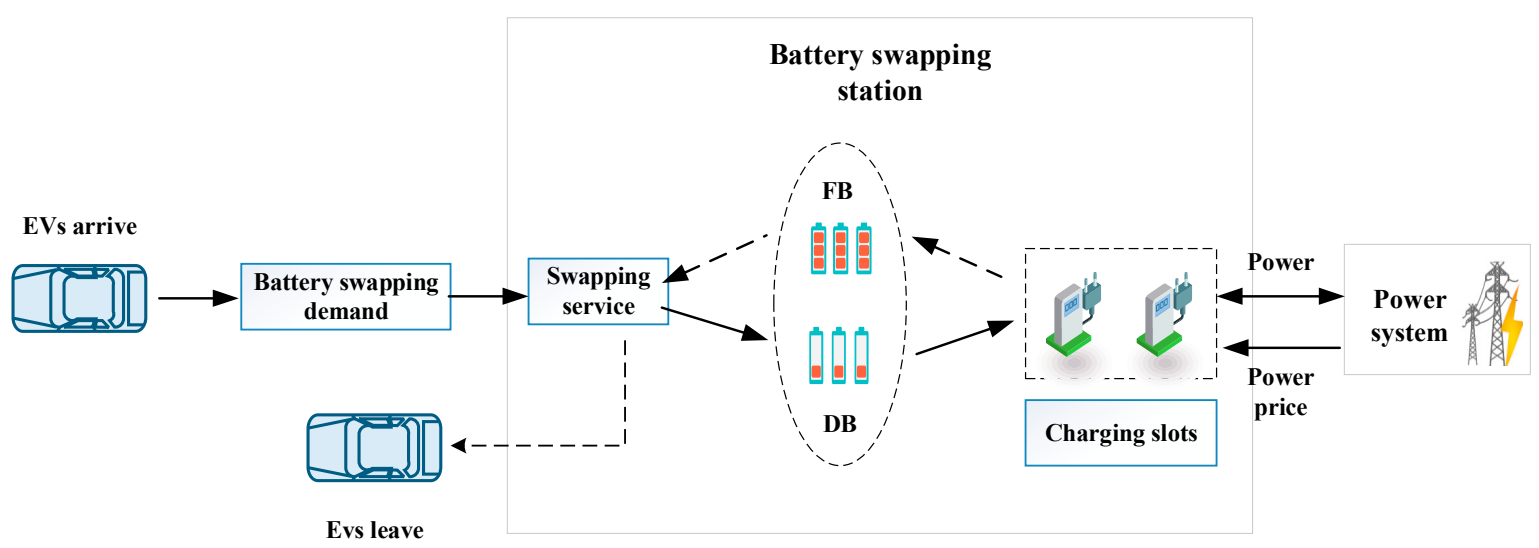

Figure 2. The operating framework of BSS. 
However, it also faces some challenges:

- High construction investment cost. Battery cost is very expensive-too many batteries increase costs, and too few batteries cannot meet customer demand.

- Heavy power grid pressure caused by disordered charging of batteries. Both fast charging and slow charging will cause load pressure on the power grid with the popularity of electric vehicles.

- Unbalanced utilization of battery swapping stations. Some electrical changing stations are congested due to excessive demand, and some are idle.

In order to solve the above problems effectively, scholars conducted research on the operation of BSS. At present, there is a lack of systematic reviews of battery swapping stations. Therefore, the purpose of this paper is to summarize the existing research on the construction, planning, and operation of battery swapping stations and put forward the future research prospect from the perspective of management and operation. The remainder of this paper is structured as follows: A general overview is presented in Section 2. Section 3 reviews the literature on battery swapping infrastructure construction and planning, followed by reviewing the battery charging strategy literature in Section 4 . Section 5 reviews the literature on alleviating the congestion of battery swapping stations. Section 6 introduces some other studies on the management and operation of battery swapping stations. In Section 7, a simple case study is conducted to illustrate the BSS model and estimate the profitability of BSS, and this paper concludes and presents future works in Section 8.

\section{General Overview}

In this paper, CiteSpace was selected to search and analyze the relevant literature on the service and operation of electric vehicle BSS reflected by the core collection of Web of Science. At first, we searched the core collection of Web of Science with "keywords = battery swap" and obtained 532 related studies. Secondly, although the database filters articles containing keywords, there are still articles unrelated to the operation of electricity exchange services. For example, their topics are system architecture design, mechanical arm design, speed profile optimization, etc. These documents are not included in this paper. Finally, 332 papers were screened. As the operation problems of electric vehicles are mainly studied by transportation, management science and electric energy research organizations, most articles involve modeling methods. Therefore, according to the typical models involved, the selected papers are divided into three categories: charging infrastructure planning, electric vehicle charging operation and vehicle scheduling.

Figure 3 shows the number of published documents on the service and operation of electric vehicle battery swapping stations every year. As shown, there are almost no relevant studies before 2008, only one in 2008, and only 10 articles per year on average from 2009 to 2013. After 2014, especially in 2018, there was a sudden increase in articles, which stabilized after 2019. A possible reason for this is that after the failed attempts of Tesla and Better Place, battery swapping was put on hold for a long time. Chinese operators have also mainly developed charging infrastructure and have not explored swapping stations. It was in 2016 that the Chinese government and enterprises re-emphasized battery swapping.

Figure 4 is a cluster analysis of keyword co-occurrence in relevant literature on BSS using CiteSpace, aimed at finding research content that many scholars pay more attention to. According to the clustering results of CiteSpace, there are mainly 8 typical clusters in the field of the service and operation of BSS. The order is from 0 to 7 . The smaller the number, the more keywords included in the cluster. Class 0 and 5 belong to the basic research object and the overall category because the analyzed documents are all related to the service and operation of electric vehicle substations. This paper mainly analyzes their specific research contents. Class 1 is vehicle to grid, that is, the reverse transmission of electric vehicles to the power grid; and the sixth type of power cost is related to the interaction of the power grid, which involves the study of charging load and charging strategy. The second constraint planning discusses the service optimization under various constraints, such as the capacity 
limitation of the substation and the power of the power system. The third kind, logistics, and the eighth kind, route optimization, are related to logistics problems, involving the study of location and vehicle route problems (VRP). The fourth category is the optimization problem, which shows that many scholars analyze the problem from the perspective of operational optimization. Through the following classification and the combination of keywords, the research contents can be roughly divided into the following three categories: facility location, power grid interaction and vehicle routing. This paper will also sort out and summarize the relevant research on the service operation of battery swapping stations from the above three categories.

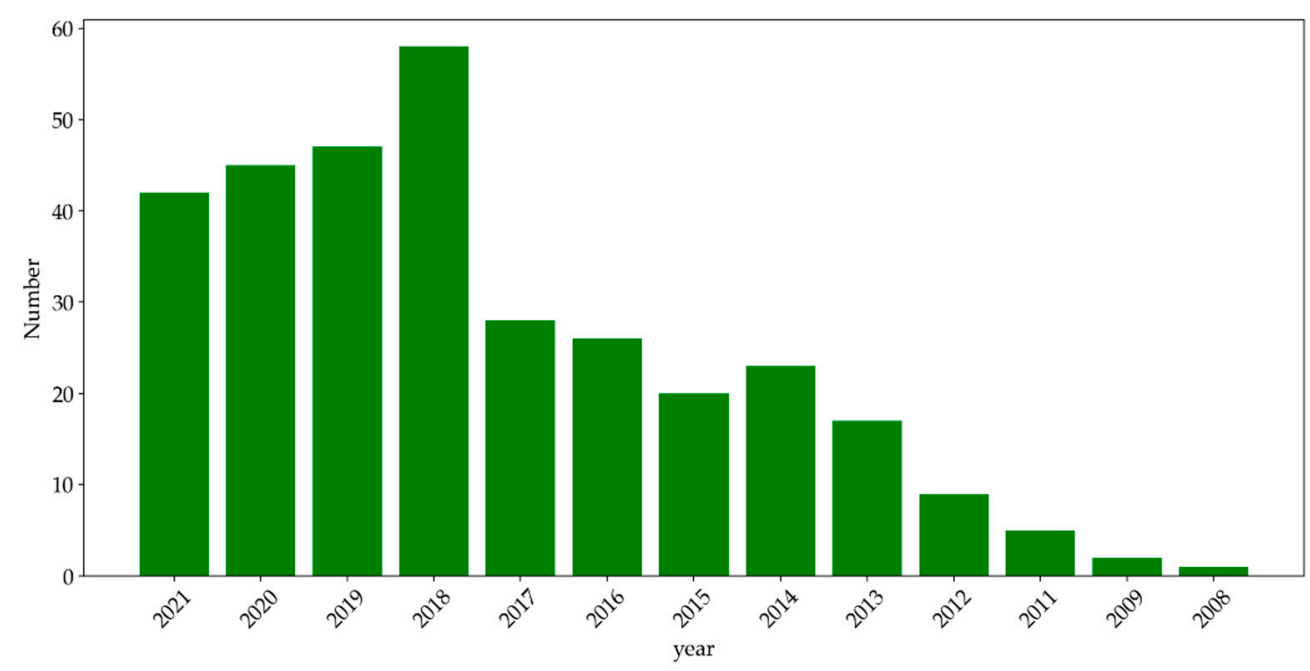

Figure 3. Published number of literature related to the service and operation of BSS.

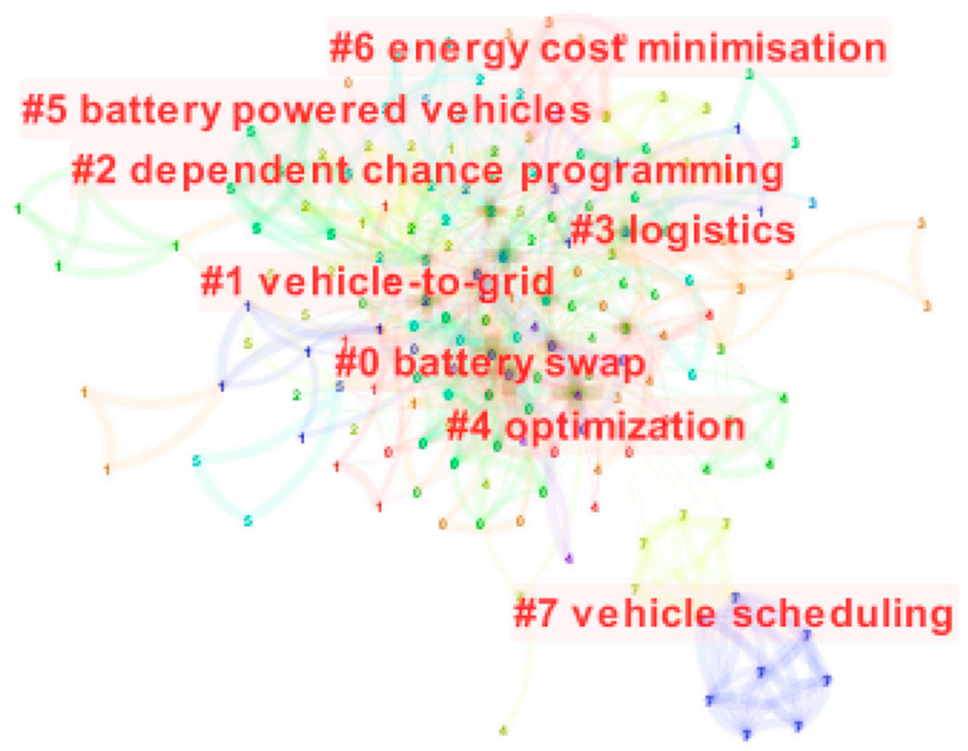

Figure 4. Cluster analysis of keywords in related literature on power stations.

\section{Construction and Planning of Battery Swapping Infrastructure}

3.1. Deployment of Battery Swapping Stations

In order to ensure the availability of charging capacity and promote the development of electric vehicles, extensive basic charging facilities must be established. Based on the classical location theory, many studies have incorporated the charging characteristics of electric vehicles into the optimization model to locate the charging infrastructure. The location model of electric vehicles is greatly inspired by the early gas station location problem. Based on the assumption of refueling demand, the proposed models can be 
divided into node-based, arc-based and flow-based models [22]. Different from the nodebased model, the flow-based model assumes that the refueling demand exists in the form of traffic flow passing through refueling facilities, which is more in line with the reality [23]. The model is derived from the concept of maximum coverage, and its goal is to capture traffic flow as much as possible on the basis of locating $\mathrm{P}$ facilities. On this basis, many scholars have extended this to the problem of charging stations and site selection of power exchange stations. This paper mainly summarizes the site selection of power exchange stations.

On the basis of the flow-based location model, the location problem of a battery swapping station based on two objectives is proposed, then two distributed robust optimization models are established and approximated as mixed-integer second-order cone programming to determine the boundary which was solved by CPLEX [6]. When electric vehicles drive on expressways, it is easy to run out of electric power due to the long distance. Then, the integer programming model is constructed under the traffic flow determination scenario and the genetic algorithm is used to solve the problem. Secondly, under random conditions, an opportunity constraint model considering the service level is constructed, and the genetic algorithm and simulation method are used to solve the problem. The results show that the location of the BSS can be arranged in high-profile areas, highway intersections and high-traffic areas [24]. Considering traffic and weather conditions, a two-stage model was proposed to solve the BSS location problem and minimize the sum of construction and operation costs [25]. The network equilibrium framework is another solution to address the location problem [26]. The authors propose mixed-integer non-linear programming, which combined the driver's route selection with the charging decision. In addition to flow-based location and network equilibrium, some scholars have proposed data-driven methods to solve the location problem. For instance, a data-driven framework is proposed to solve the PROBLEM of BSS positioning based on GPS data of taxi in large cities $[27,28]$. Through region matching and trajectory extraction using the Hidden Markov Model (HMM), the power consumption process of electric vehicles is inferred, and then the space-time distribution of power exchange demand is obtained by clustering calculation. Finally, places with dense battery demand are selected as BSS location candidates. Research shows that the average distance error between the power demand position and the nearest BSS calculated by this method is reduced by $52.5 \%$ and $62.7 \%$, respectively. In addition, the land occupation cost of BSS, the comfort of drivers and the impact on the load level of the power grid may all be factors affecting the location of BSS, and the comprehensive evaluation model for the location of BSS from three angles of economy, society and technology was put forward for the first time [29].

\subsection{Location-Routing Problem}

In addition to the basic location problem, another research branch is to consider the vehicle route when determining the optimal location of the substation, that is, the popular location-routing problem. Location problems are usually aimed at minimizing the construction cost and transportation cost of the power station, for which the tabu search algorithm and the mileage-saving algorithm can be used. However, electric vehicles are only allowed to visit customers once [30]. On this basis, there are other authors who assume that customers can be visited many times and adopt the adaptive large neighborhood search algorithm to determine the location of BSS [31]. Then, the impact of BSS on the distribution network is also considered [32]. With the development of research, the two-stage vehicle routing problem of electric vehicles with time windows and battery swapping stations was put forward $[33,34]$. On the first floor, large-capacity electric vehicles are used to transport goods from storage to the distribution center; and on the second floor, small-capacity electric vehicles are used to provide services for customers from the distribution center who visit the battery swapping station many times. In this paper, an integer programming model is built with the goal of minimizing transportation cost, the loading and unloading cost of the distribution center and battery exchange cost, which is solved by the gurobi exact 
solution, the column generation algorithm and the adaptive large neighborhood search algorithm. Wind energy also be used in power supply. In [35], the battery distribution path is considered under the centralized charging and unified distribution mode. A joint optimal scheduling model of the wind power generation plan, battery exchange demand, battery charge and discharge and VRP is established, and the model is solved by the genetic algorithm. The dynamic programming algorithm [36], the mixed-variable neighborhood search (HVNS) [37], the adaptive genetic algorithm [38] and the colony algorithm [39] are also effective algorithms to solve mathematical models. These studies are summarized in Table 3, which includes the research objective, the optimization model, and the solution method for the optimization step.

Table 3. Collation of key documents of BSS planning.

(1) Deployment of Battery Swapping Stations

\begin{tabular}{|c|c|c|c|}
\hline References & Target & Model & Solution Method \\
\hline Mak et al. (2013) & $\begin{array}{l}\text { Minimize the cost in the worst } \\
\text { case; maximize the probability of } \\
\text { the worst case }\end{array}$ & $\begin{array}{l}\text { Distributed robust } \\
\text { optimization }\end{array}$ & CPLEX \\
\hline Yang and Sun (2015) & $\begin{array}{l}\text { Minimize construction cost and } \\
\text { inventory cost }\end{array}$ & $\begin{array}{l}\text { Mixed-integer linear } \\
\text { programming }\end{array}$ & Genetic algorithm \\
\hline An et al. (2020) & Minimize construction cost & $\begin{array}{l}\text { Two-stage stochastic } \\
\text { programming model }\end{array}$ & Gradient descent algorithm \\
\hline He et al. (2015) & Minimize the total social cost & $\begin{array}{l}\text { Mixed-integer non-linear } \\
\text { programming }\end{array}$ & Genetic algorithm \\
\hline Zeng et al. (2019) & $\begin{array}{c}\text { Reduce the average distance error } \\
\text { between power demand point } \\
\text { and BSS }\end{array}$ & Hidden Markov Model & $\begin{array}{l}\text { Map matching algorithm based on } \\
\text { hidden Markov: trajectory reduction } \\
\text { algorithm (TTR); K-means clustering; } \\
\text { hierarchical clustering }\end{array}$ \\
\hline Wang et al. (2019) & Minimize cost & $\begin{array}{l}\text { System dynamics model; } \\
\text { space-time distribution } \\
\text { model of electricity demand }\end{array}$ & $\begin{array}{l}\text { Improve the difference algorithm; } \\
\text { Monte Carlo search }\end{array}$ \\
\hline
\end{tabular}

(2) Location-Routing Problem

\begin{tabular}{cccc}
\hline Yang and Sun (2015) & $\begin{array}{c}\text { Minimize construction and } \\
\text { transportation costs }\end{array}$ & $\begin{array}{c}\text { Mixed-integer linear } \\
\text { programming }\end{array}$ & $\begin{array}{c}\text { Taboo search; improve mileage } \\
\text { saving; four-stage heuristic algorithm: } \\
\text { scanning algorithm, iterative greed, } \\
\text { adaptive large neighborhood, CPLEX }\end{array}$ \\
\hline Hof et al. (2017) & $\begin{array}{c}\text { Minimize construction and } \\
\text { transportation costs }\end{array}$ & $\begin{array}{c}\text { Mixed-integer linear } \\
\text { programming }\end{array}$ & $\begin{array}{c}\text { Adaptive large neighborhood search } \\
\text { algorithm }\end{array}$ \\
\hline Jie et al. (2019) & $\begin{array}{c}\text { Minimize transportation costs, } \\
\text { distribution center handling costs, } \\
\text { and battery exchange costs }\end{array}$ & $\begin{array}{c}\text { Bilevel integer } \\
\text { programming }\end{array}$ & $\begin{array}{c}\text { Gurobi; column generation algorithm; } \\
\text { adaptive large neighborhood search } \\
\text { algorithm }\end{array}$ \\
\hline Li et al. (2020) & $\begin{array}{c}\text { Minimize the total cost associated } \\
\text { with energy consumption and } \\
\text { travel time of electric vehicles }\end{array}$ & Mixed-integer programming & $\begin{array}{c}\text { Adaptive genetic algorithm based on } \\
\text { climbing optimization and } \\
\text { neighborhood search }\end{array}$ \\
\hline
\end{tabular}

\subsection{Inventory Problem of Battery}

How many batteries should be stored in the battery swapping station is a very important decision in the early stage. It is of practical significance to determine the number of batteries and chargers under the background of the random arrival of automobiles, random battery status and random charging time [40,41]. It is ideal to improve battery availability by replacing exhausted batteries immediately upon arrival at the battery swapping station and charging them at the same time, but the charger and battery costs are the main factors affecting the battery inventory [42]. Therefore, a mathematical model aiming at the 
annual average cost of facilities and taking the scale of power stations and daily battery exchange demand as constraints is established, which is solved by the differential evolution method [43]. This method ignores the battery charging cost. The BSS optimization model with the largest battery inventory can be built by optimizing the battery charging mode, and then different charging schemes are designed to minimize the battery cost, such as the battery optimization for Hong Kong airport bus station [44]. The scale and capacity mentioned above are hard constraints, and customer waiting time can also be used as a soft constraint that affect the capacity of electrical changing stations. In [45], the authors constructed an optimization model of the power station aiming at minimum investment, minimum maintenance and minimum charging cost, and restricted extra waiting time (EWT) of electric vehicles as the service quality. By simulating the states of electric vehicles and batteries under different operation strategies, the EWT of each electric vehicle is calculated, and the quantitative relationship between electric vehicles, batteries and chargers under different EWT levels is obtained, which provides a reference for the configuration number of batteries and chargers in the substation. The process of vehicles arriving at stations to receive services is actually a hybrid queuing network, and the queuing theory can also be used to solve the problem of capacity optimization [46].

\section{Battery Charging Strategy}

Optimization of the charging strategy can maximize the inventory turnover rate or minimize the impact of charging on the power system [47]. According to the research objectives, charging strategies are mainly based on three factors: (1) reducing grid load, in order for the smooth operation of the power grid and enable only small fluctuations in charging load; (2) from an economic point of view, achieving maximum benefit or lowest cost of battery swapping stations; (3) from the perspective of queuing theory, the main indicators considered are blocking degree and the service level.

\subsection{Reduce Grid Load}

Compared with disordered charging, the optimal charging model based on charging load prediction can significantly reduce the charging cost and load variance [48]. On the basis of charge load simulation, scholars have carried out research on effective control of charge load and minimizing battery charging damage $[49,50]$. In order to smooth load fluctuation, the authors adopted the improved Shuffled Frog Leading Algorithm (ISFLA) to study the coordinated charging strategy [51,52]. Compared with particle swarm optimization, the improved Shuffled Frog Leading Algorithm has a faster convergence speed and higher accuracy, and can reduce the peak-valley difference and smooth load distribution. The multi-population particle swarm optimization algorithm also optimizes the charging strategy. The algorithm overcomes the shortcoming of particle swarm optimization (PSO), which is limited to the local optimum, realizes the orderly charging and discharging of the battery charging and discharging station, and realizes the peak shaving function of the power grid [53]. In terms of driver battery swapping behavior, the optimal charging mode also has an impact on the grid side and the generation side. Load fluctuation rate, peak-valley difference and load ratio are used to evaluate charging load optimization. The empirical results show that OCM is helpful to balance the power load and reduce the difference between peak and valley load. For the generator, OCM can reduce coal consumption and the cost of the generator set [54]. The above approach usually involves assuming a requirement. In [55], applied deep reinforcement learning and a BSS model are proposed to determine the optimal real-time charging and discharging power of charging piles. The model can directly obtain the predictability of the bus operation and the uncertainty of price from historical data, without making any assumptions in the model. In addition, the depth deterministic strategy gradient is introduced into the model as the DRL algorithm, which can control multiple charging piles at the same time. Numerical results show that this method not only provides enough batteries for exchange, but also brings lower operating costs than the existing benchmark control method. 


\subsection{Queuing Theory}

Most of the studies from the perspective of the queuing theory simultaneously optimize the number of batteries and charging plan. Under the framework of Markov (MDP), dynamic programming and the Mon-Takalo approximation algorithm were used to determine the quantity and charging capacity of batteries, and it was elaborated that the operation cost of batteries could be reduced by lateral transportation among multiple power stations [19]. On the basis of reference, the charging operation problem can be expressed as a stationary constrained Markov decision process, which ensures a certain quality of service and minimizes the charging cost [56]. Markov processes have a finite horizon, discrete time and are non-stationary. Assume that the BSS can release electric energy back to the power grid, but the waiting cost caused by the backlog of battery demand is not considered, which makes the BSS charging operation based on the current battery charging technology too simple [57]. Subsequently, a periodic fluid model was proposed to describe the charging operation of BSS with time-varying battery demand and time-varying battery charging price. Taking the investment cost and operation cost of batteries (including charging cost and waiting cost of users) as the target, and taking the congestion as the service level of the power exchange station as an important part of the operation cost, the optimal battery purchase quantity and the charging strategy are found [20]. Paper [58] introduced a stochastic scheduling, allocation and inventory replenishment problem (SAIRP) with the interaction of primary inventory (battery charging) and secondary inventory (battery capacity). Considering the influence of battery degradation on the battery replacement system, this problem is solved by the backward induction method, so as to determine the optimal strategy of the number of batteries that need to be charged, discharged and replaced with time under the conditions of an unfixed charging price, an unfixed discharge income and an capacity-related exchange income.

\subsection{Economic Perspective}

Optimization of the charging strategy can be studied based on the time-of-use power price, which is aimed at the income of the battery swapping station considering constraints such as the charging and discharging capacity of the BSS and the electricity demand of electric vehicles [59]. For example, in the interactive operation mode of EVs and BSS based on a smart microgrid, the power price incentive model is used to generate a management strategy for coordinating the charging of electric vehicles and BSS, so as to minimize the total cost of electric vehicles and maximize the profit of BSS [60-62]. Alternatively, the charging and discharging process of batteries in BSS can be coordinated by increasing the number of batteries in BSS and setting a stepped electricity price [63]. These studies are summarized in Table 4.

Table 4. Battery charging strategy of BSS.

\begin{tabular}{cccc}
\hline References & Target & Model & Solution Method \\
\hline Wu et al. (2017) & $\begin{array}{c}\text { Improve BSS battery inventory } \\
\text { level and minimize battery } \\
\text { charging damage }\end{array}$ & Multi-objective optimization model & $\begin{array}{c}\text { Genetic algorithm; differential } \\
\text { evolution algorithm; particle } \\
\text { swarm optimization algorithm }\end{array}$ \\
\hline $\begin{array}{c}\text { Huang et al. (2013) } \\
\text { Zhao et al. (2017) }\end{array}$ & $\begin{array}{c}\text { Improve BSS battery inventory } \\
\text { level and minimize battery } \\
\text { charging damage }\end{array}$ & Multi-objective optimization model & $\begin{array}{c}\text { Genetic algorithm; differential } \\
\text { evolution algorithm; particle } \\
\text { swarm optimization algorithm }\end{array}$ \\
\hline Gao et al. (2015) & Restrain load fluctuation & $\begin{array}{c}\text { Charge scheduling model with } \\
\text { charge and discharge power in } \\
\text { different periods as constraints }\end{array}$ & $\begin{array}{c}\text { Multi-population particle } \\
\text { swarm optimization algorithm }\end{array}$ \\
\hline Gao et al. (2020) & $\begin{array}{c}\text { Optimal real-time charging and } \\
\text { discharging strategy }\end{array}$ & Reinforcement learning model & DRL algorithm \\
\hline
\end{tabular}


Table 4. Cont.

\begin{tabular}{ccc}
\hline References & Target & Model \\
\hline Sun et al. (2019) & $\begin{array}{c}\text { Minimize battery investment } \\
\text { cost and operating cost }\end{array}$ & $\begin{array}{c}\text { Periodic fluid model; queuing } \\
\text { theory }\end{array}$ \\
\hline Widrick et al. (2018) & profit maximization & Markov decision processes \\
\hline Asadi et al. (2021) & $\begin{array}{c}\text { Reduce the charging cost; } \\
\text { Optimize number of batteries }\end{array}$ & Markov decision processes \\
Liang et al. (2017) & Maximize the operating profit \\
of the power station & $\begin{array}{c}\text { Linear programming constrained } \\
\text { by electricity exchange demand and } \\
\text { battery charge and discharge } \\
\text { balance }\end{array}$
\end{tabular}

\section{Assignment Problem of BSS}

Similar to the charging strategy, the scheduling of the battery swapping station is also an important issue. Literature related to the scheduling problem can be divided into two parts. One is the traditional vehicle route problem (VRP), which mainly includes the route selection of private users, goods distribution and the battery distribution between charging stations and BSS. The second is to reduce congestion by assigning battery swapping stations. Operators usually build multiple battery swapping stations in a city. When the service resources of one station are in short supply and the battery inventory of the other station is sufficient, the demand scheduling of this station can be transferred to other stations through decision optimization. However, the actual situation is that there are often some battery swapping stations with excessive demand, which leads to traffic congestion, while some stations are left unattended, thus losing the construction cost of the station operators and reducing the service level. Therefore, this paper analyzes the relevant research on assigning battery swapping stations to reduce congestion. As the VRP problem is a classic and widely studied problem, it is not a special problem unique to battery swapping stations, and it has been combed in the third part in combination with the location problem, so this part will not repeat mention of the VRP literature. For a detailed literature review of VRP, please refer to $[64,65]$.

The selection of a battery swapping station can be discussed from three aspects: the research objective, the research object and the solving algorithm. Firstly, considering the battery charging situation, the mileage of electric vehicles and the traffic situation, the real-time scheduling problem of recommending a replacement station for electric vehicles is studied. In view of the discreteness of BSS assignment and strong non-linear coupling in time and space, a method of repeating potential game theory to approximate the original problem is proposed, and thus a sub-optimal solution can be efficiently obtained using the distributed iterative optimal response algorithm. In this work, the basic modeling and approximate solution are discussed preliminarily, but the theoretical performance cannot be guaranteed [66]. Then, aiming at reducing the total cost of electric vehicles and station congestion caused by the temporary shortage of available batteries, the author discussed the optimal station allocation problem for battery swapping of electric vehicles, and optimized the problem using the Hungarian algorithm and the bipartite graph matching algorithm $[67,68]$. In addition, the distribution of BSS can be optimized by combining the interaction of the microgrid, and a second-order conical programming relaxation method is proposed to solve BSS, aiming at minimizing the driving distance and the power generation cost of electric vehicles. However, the algorithm is only suitable where the same operator manages the distribution network, the battery swapping station and the electric vehicle centrally [69]. If organizations are independent of each other and information is not shared, two distributed solutions based on a multiplier alternating direction method and dual decomposition can be used for optimization [70]. The queuing theory can also be used to set two thresholds in the queue, and the battery power supply interval and the arrival interval of electric vehicles are dynamically controlled according to the packet queue size. 
Using embedded Markov chain and supplementary variable technology, the queue length distribution of vehicles at departure time and at any time is derived so as to ease the congestion of the battery switching station and improve the utilization rate [71]. These studies are summarized in Table 5.

Table 5. Assignment problem of BSS.

\begin{tabular}{cccc}
\hline References & Target & Model & Solution Method \\
\hline You et al. (2016) & $\begin{array}{c}\text { Relieve the congestion of } \\
\text { changing stations }\end{array}$ & Game theory & Game theory \\
\hline You et al. (2017) & $\begin{array}{c}\text { Relieve the congestion of } \\
\text { changing stations }\end{array}$ & $\begin{array}{c}\text { Mixed-integer linear } \\
\text { programming }\end{array}$ & $\begin{array}{c}\text { Hungary algorithm; } \\
\text { second-order cone } \\
\text { programming }\end{array}$ \\
\hline Choi et al. (2020) & $\begin{array}{c}\text { Relieve the congestion of } \\
\text { changing stations }\end{array}$ & $\begin{array}{c}\text { Markov decision } \\
\text { processes }\end{array}$ & $\begin{array}{c}\text { Markov decision } \\
\text { processes }\end{array}$ \\
\hline
\end{tabular}

\section{Other Relevant Research}

Some scholars have also studied battery management technology, wind power generation, supplier selection and secondary utilization of battery energy storage.

State of charge for lithium batteries is one of the important parameters of battery management system, and also the basis for charge and discharge control strategies and battery balance. In order to improve SOC prediction accuracy, a model based on the longterm and short-term memory (LSTM) recursive neural network (RNN) is constructed to describe the electrical performance of batteries. Then, an improved square root-cubature Kalman filter (SRCKF) is designed to estimate the battery cell's SOC [72]. Considering the widespread hysteresis in lead-acid batteries, the SOC estimation technique based on differential evolution was adopted to minimize the hysteresis effect and realize the accurate estimation of SOC [73]. As a general view, many scholars have made a detailed review on SOC estimation [74-77].

Papers [78] studied a battery charging system (W-BSCS) based on a wind farm. In W-BSCS, the wind farm not only supplies power to the power grid, but also cooperates with the centralized charging station (CCS) to charge the batteries of electric vehicles and distribute them to multiple BSS. On this basis, joint optimal scheduling model for wind power generation planning, battery swapping demand, battery charging and discharging and vehicle routing problem is established. Then the heuristic method of exhaustive search and the genetic algorithm are used to solve the NP hard problem.

In terms of battery supplier selection, the authors propose a framework for sustainable selection of battery suppliers based on multi-criteria decision making (MCDM). Firstly, two new standards are proposed based on the different requirements of BSS and new energy vehicle manufacturing. Then, the triangular fuzzy number is used to deal with the uncertainty and fuzziness in the decision-making process. Finally, the triangular fuzzy entropy weight method is used to determine the weight of the criteria, and the MULTIMOORA method is used to sort the schemes. This paper provides a key tool for investors to choose the most suitable BSS battery supplier [79].

By responding to the market incentive mechanism, the waste batteries of electric vehicles can be used as retired battery energy storage systems (RBESSs) of battery swapping stations, so as to improve their economic profitability and operational flexibility. In order to maximize the annual revenue of BSCS, a two-stage coordinated decision-making (DCD) framework for BSCS configuration is established using the distributed robust optimization (DRO) method. Through a large number of simulations and comparative studies, the effectiveness and superiority of the proposed BSCS DCD framework are verified. The proposed overall optimization method will contribute to the safe, reliable and economical operation of next-generation power grid, and at the same time improve the economy and utilization rate of the batteries of retired electric vehicles [80]. 


\section{Feasibility Analysis of Battery Swapping Station}

\subsection{Business Model of BSS}

This section conducts a feasibility analysis on the future operation of BSS. Firstly, several typical modes in the development process of BSS are briefly described, and then the profitability of BSS is estimated. Finally, applicable conditions for implementing the battery swapping mode are elaborated. Information about BSS is obtained from White Paper on the technical development of electric vehicle charging facilities in China.

\subsubsection{Case 1: Better Place}

Better Place pioneered the business model of battery swapping and built a complete battery swapping network. Figure 5 shows the Better Place battery swapping business model. Better Place buys vehicles and batteries from car companies, and users swap their batteries at Better Place, renting different batteries. Analysis of its failure:

- The market space of the new energy industry was small initially, so it was difficult to cover the huge investment in the early stage.

- Better Place did not have the capacity to produce a car and sold too few batteryswitched vehicles.

- Better Place was cash strapped and could not continue to operate.

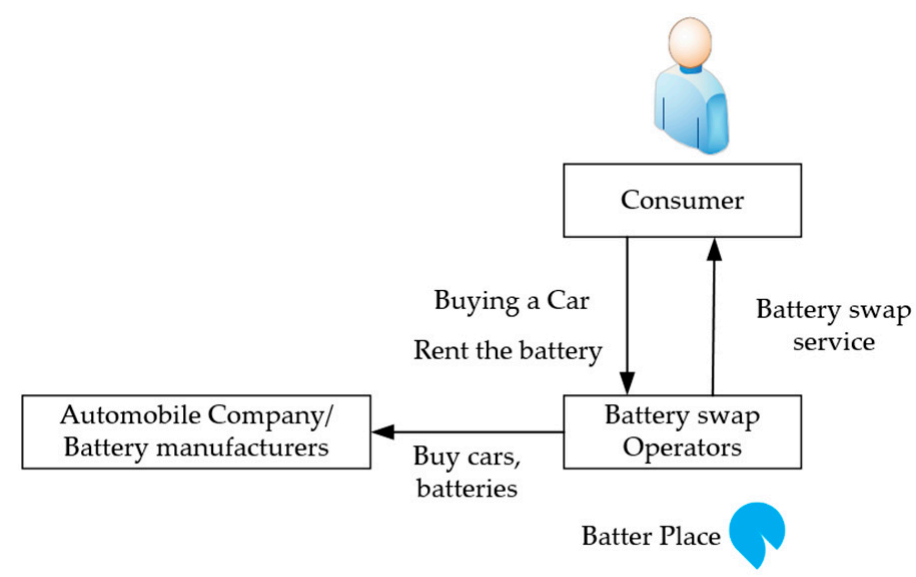

Figure 5. Battery swapping business model of Better Place.

\subsubsection{Case 2: Tesla}

Figure 6 shows the Tesla battery swapping business model. Tesla launched a battery swapping service offering two options. With the first option, customers could keep their replacement batteries by meeting the price difference based on the difference between their batteries and the new batteries. The second option offered customers a $\$ 60$ to $\$ 80$ service fee to swap back for their original batteries. Analysis of its failure:

- Customers had to pay a service fee although a large number of charging stations were installed.

- Batteries could not be shared across vehicle models.

- The cost of construction the battery swapping stations was too high. 


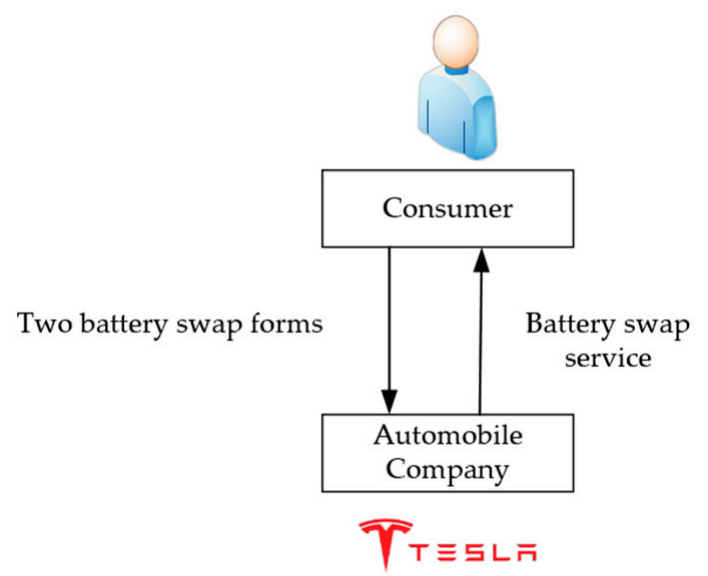

Figure 6. Battery swapping business model of Tesla.

\subsubsection{Case 3: Business Model of Chinese Enterprises}

The development of the battery swapping mode in China was not smooth until 2018, which bought rapid development. Many enterprises in China have participated in the construction planning of electrical changing stations. At this stage, capital injection has promoted the integration of the industrial chain, and application scenarios including operation vehicles, commercial vehicles and private cars have generally been diversified. Figure 7 shows the battery swapping business model of Chinese enterprises. A variety of factors catalyzed rapid development in the battery swapping industry in China [23]:

- Business models are maturing.

- National policies support battery swapping, make provisions on battery standards and there are battery swapping safety requirements.

- Technology is constantly upgrading. The fastest change time has been reduced to $90 \mathrm{~s}$.

- More enterprises are joining the battery swapping industry.

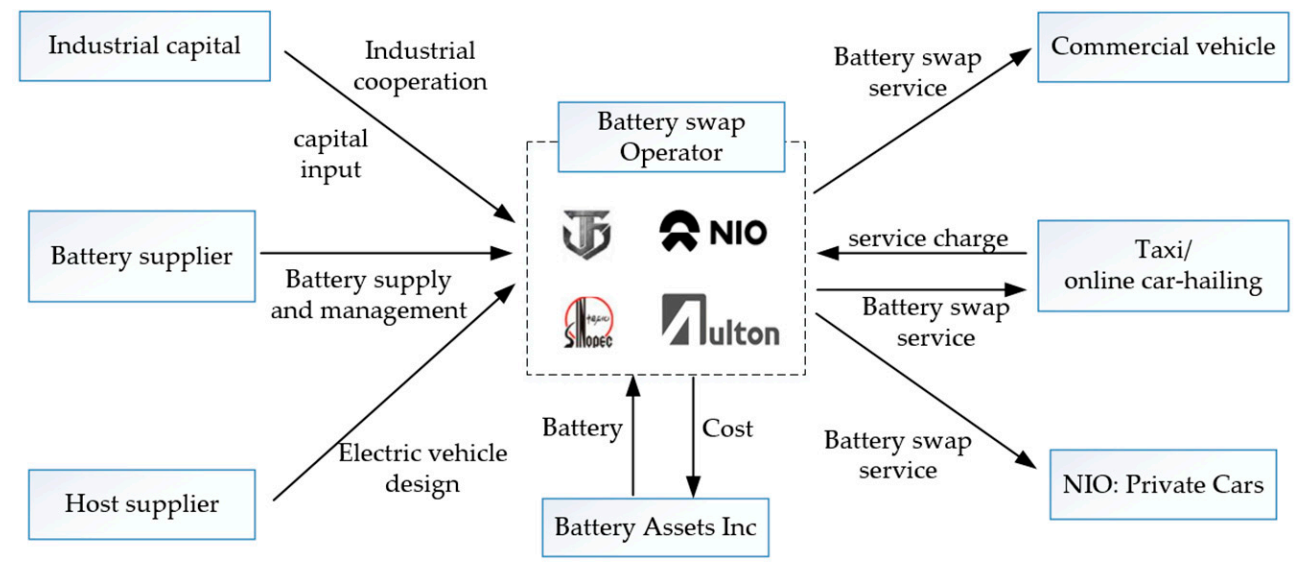

Figure 7. Battery swapping business model of Chinese enterprises.

\subsection{Profitability Analysis}

Is it feasible to build electrical changing stations? Figure 8 shows the number of BSS in China from January to October 2021. There was an increase of 93\% in October compared with January. At present, China has largely promoted the battery swapping mode to taxi, online car-hailing, and commercial vehicles. All taxis in Beijing are required to be replaced with electric vehicles. China has issued a number of policies to promote the development of battery swapping. 


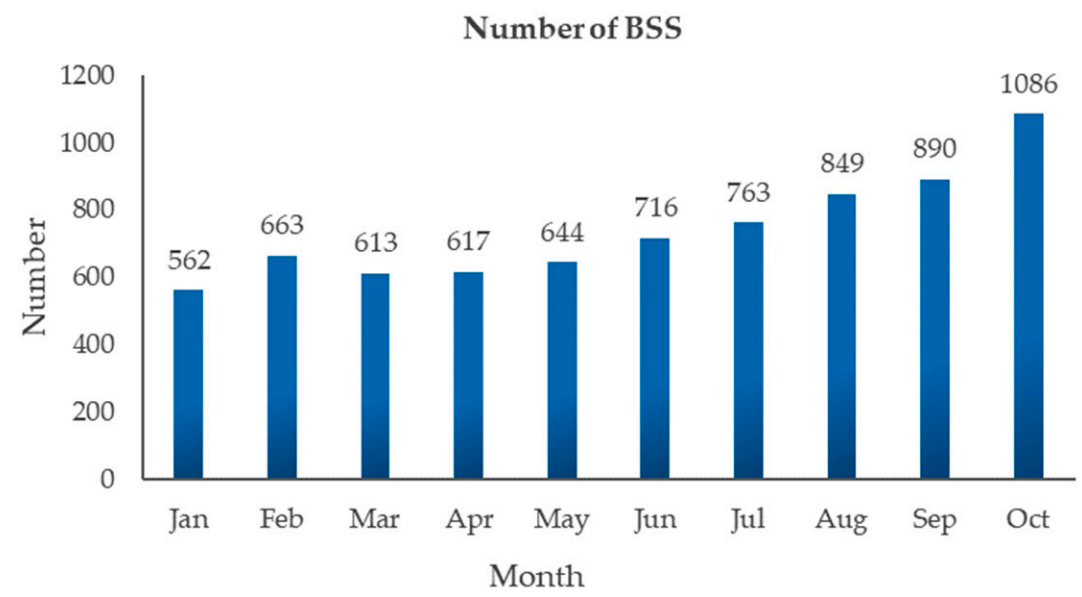

Figure 8. Number of BSS in China from January to October 2021. Data source: China Electric Vehicle Charging Infrastructure Promotion Alliance.

Figure 9 shows the return on investment (ROI) of BSS, based on the factors including policy, technology, number of EVs and enterprises-whether China's battery swapping stations can be profitable. Founder Securities, a Chinese securities firm, has estimated the profitability of BSS by surveying 31 firms. The profit of BSS consists of three parts: cost, revenue and battery depreciation. The cost mainly includes equipment, batteries, operation, rent, labor and financial expenses. The revenue mainly comes from users' battery swapping. Finally, taking taxi and online car-hailing vehicles as examples, the ROI based on different frequencies of battery swapping is calculated. As shown in Figure 8, assuming that the electricity price is $1.75 \mathrm{yuan} / \mathrm{Kwh}$, the battery swapping station can only make a profit by serving customers at least 33 times a day.

the ROI under different frequency of battery swapping service

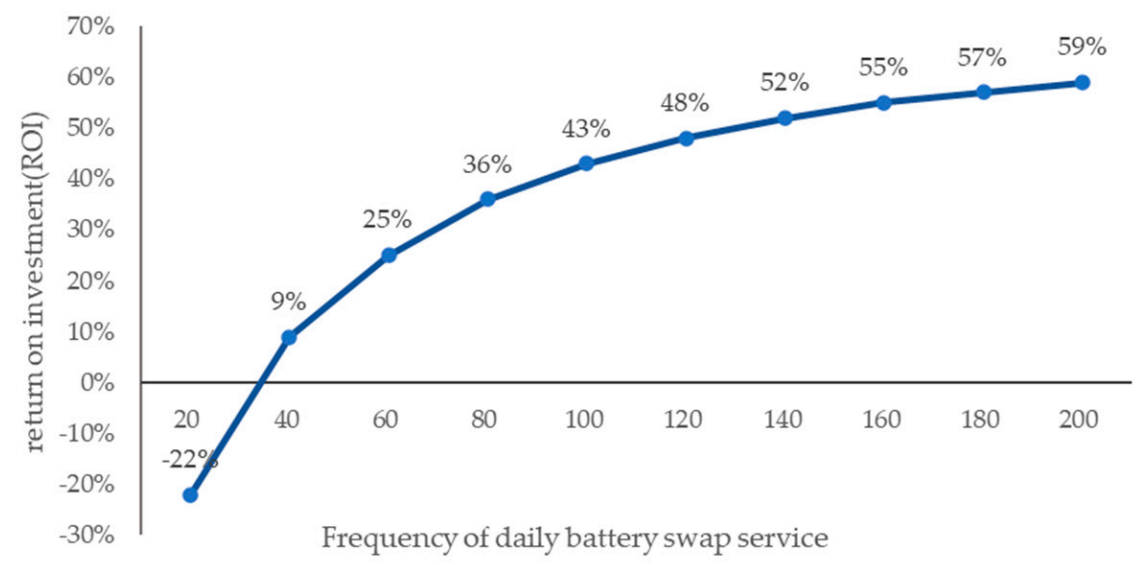

Figure 9. The ROI based different frequencies of battery swapping.

To summarize, based on the experience of Better Place, Tesla and Chinese enterprises, several basic conditions must be met to develop the battery swapping industry: national policies, the involvement of battery manufacturing companies and electrical vehicles manufacturers and battery swapping service systems. In terms of application, BSS are currently more suitable for taxis, logistics vehicles, electric buses and other public demand vehicles. In the future, more private users will participate in battery swapping, such as $\mathrm{NiO}$ in China. 


\section{Conclusions}

In this paper, the service and operation of electric vehicle power stations were reviewed. The first part briefly described the background of the development of electric vehicles and emphasized several obstacles to the popularization of electric vehicles. Then, the types of existing charging modes of electric vehicles were summarized, and the existing problems of charging modes were elaborated. On this basis, this paper puts forward a battery swapping mode that can quickly replenish electric energy and has summarized its development course. In the second part, the documents retrieved from the core collection of Web of Science were visually analyzed using CiteSpace visualization tool, and the research issues related to the operation planning of electric vehicles were mainly divided into three categories, namely, the construction planning of BSS, charging strategies and BSS selection. Finally, the analysis results were obtained through literature review and future research directions were proposed and discussed.

(1) The existing research on the battery swapping station focuses on the location problem and charging strategy optimization, while the research on the number of batteries in the early stage of the BSS is scant. Some articles regard the initial battery reserve quantity as a fixed value that must be met while other articles utilize sensitivity analysis in determining the the battery reserve, without related research modelling the battery reserve.

(2) Optimization of the electric vehicle charging strategy has become a hot topic in recent years, and has also achieved rich research results. However, under the current development mode of BSS, there are some limitations for practical engineering applications. First, most studies directly control the load on the power grid from the perspective of operators, power grids and electric vehicle users, without considering the operational difficulties caused by actual user needs and user experience. Second, the current research results fully consider the peak shaving and valley filling effect brought by orderly charging under the time-of-use power price, while ignoring the restriction of the number of chargers in the BSS and the constraints of user service ability. Moreover, the research results are suitable for centralized scheduling of electric vehicles, and are not suitable for the orderly scheduling of a single vehicle or a small number of vehicles in the battery swapping mode. Third, most studies model the probability distribution of power price and battery demand by fitting statistical laws to historical data. The difference between artificial assumptions and actual uncertainties will affect the reliability of the results.

(3) At present, there are few studies on the assignment of BSS, and the existing research focuses on how to provide the best scheme for users and reduce the waiting time for power exchange in the future; how to provide users with the shortest waiting time for power exchange; how to effectively improve the utilization rate of power station. Although cooperative scheduling between moving electric vehicles and the power exchange station is considered, the following problems are not considered: when the power exchange demand increases to a certain threshold, the waiting time for power exchange is too long due to an insufficient battery reserve and the single battery swapping stations accepting excessive demand. There is usually only one optimization index, which does not have the ability for self-learning and selfimprovement of decision accuracy and reliability.

Through literature review and analysis, first, it is possible to build a battery reserve planning model based on a queueing network in combination with battery swapping requirements. Second, instead of harmonizing past data, the reinforcement learning algorithm can be directly used for data training to control the battery charging strategy. Thirdly, from the perspective of BSS operators, optimal decisions can be made using the reinforcement learning method with the goal of balancing the resource allocation of multiple swapping stations. 
Author Contributions: The authors confirm the contributions to this paper are as follows: Y.F. defined the scope and provided formal analysis of the review. X.L. assessed the relevance of papers reviewed. All authors have read and agreed to the published version of the manuscript.

Funding: This research was funded by National Natural Science Foundation of China, grant number 72171016. This research was funded by Beijing Philosophy and Social Science Foundation, grant number 20JCC005. This work is supported by Beijing Logistics Informatics Research Base.

Institutional Review Board Statement: Not applicable.

Informed Consent Statement: Not applicable.

Data Availability Statement: Data sharing not applicable, No new data were created or analyzed in this study. Data sharing is not applicable to this article.

Conflicts of Interest: The authors declare no conflict of interest.

\section{References}

1. Sobol, L.; Dyjakon, A. The Influence of Power Sources for Charging the Batteries of Electric Cars on $\mathrm{CO}_{2}$ Emissions During Daily Driving: A Case Study from Poland. Energies 2020, 13, 4267. [CrossRef]

2. Mehar, S.; Zeadally, S.; Remy, G.; Senouci, S.M. Sustainable Transportation Management System for a Fleet of Electric Vehicles. IEEE Trans. Intell. Transp. Syst. 2015, 16, 1401-1414. [CrossRef]

3. Agaton, C.B.; Collera, A.A.; Guno, C. Socio-Economic and Environmental Analyses of Sustainable Public Transport in the Philippines. Sustainability 2020, 12, 4720. [CrossRef]

4. Ahmed, M.; Zheng, Y.; Amine, A.; Fathiannasab, H.; Chen, Z. The role of artificial intelligence in the mass adoption of electric vehicles. Joule 2021, 5, 2296-2322. [CrossRef]

5. Wang, Y.-Y.; Chi, Y.-Y.; Xu, J.-H.; Li, J.-L. Consumer Preferences for Electric Vehicle Charging Infrastructure Based on the Text Mining Method. Energies 2021, 14, 4598. [CrossRef]

6. Mak, H.-Y.; Rong, Y.; Shen, Z.-J.M. Infrastructure Planning for Electric Vehicles with Battery Swapping. Manag. Sci. 2013, 59, 1557-1575. [CrossRef]

7. Zhang, Y.; Deng, J.; Zhu, K.; Tao, Y.; Liu, X.; Cui, L. Location and Expansion of Electric Bus Charging Stations Based on Gridded Affinity Propagation Clustering and a Sequential Expansion Rule. Sustainability 2021, 13, 8957. [CrossRef]

8. Wu, X.; Feng, Q.; Bai, C.; Lai, C.S.; Jia, Y.; Lai, L.L. A novel fast-charging stations locational planning model for electric bus transit system. Energy 2021, 224, 120106. [CrossRef]

9. Uslu, T.; Kaya, O. Location and capacity decisions for electric bus charging stations considering waiting times. Transp. Res. Part D Transp. Environ. 2021, 90, 102645. [CrossRef]

10. Arias-Londoño, A.; Montoya, O.D.; Grisales-Noreña, L.F. A Chronological Literature Review of Electric Vehicle Interactions with Power Distribution Systems. Energies 2020, 13, 3016. [CrossRef]

11. Wang, X.; He, Z.; Yang, J. Electric Vehicle Fast-Charging Station Unified Modeling and Stability Analysis in the dq Frame. Energies 2018, 11, 1195. [CrossRef]

12. Liu, X. Research on Flexibility Evaluation Method of Distribution System Based on Renewable Energy and Electric Vehicles. IEEE Access 2020, 8, 109249-109265. [CrossRef]

13. Lee, K.-B.; Ahmed, M.A.; Kang, D.-K.; Kim, Y.-C. Deep Reinforcement Learning Based Optimal Route and Charging Station Selection. Energies 2020, 13, 6255. [CrossRef]

14. Sierpiński, G.; Staniek, M.; Kłos, M.J. Decision Making Support for Local Authorities Choosing the Method for Siting of In-City EV Charging Stations. Energies 2020, 13, 4682. [CrossRef]

15. Wang, Y.; Bi, J.; Lu, C.; Ding, C. Route Guidance Strategies for Electric Vehicles by Considering Stochastic Charging Demands in a Time-Varying Road Network. Energies 2020, 13, 2287. [CrossRef]

16. Ferro, G.; Paolucci, M.; Robba, M. Optimal Charging and Routing of Electric Vehicles with Power Constraints and Time-of-Use Energy Prices. IEEE Trans. Veh. Technol. 2020, 69, 14436-14447. [CrossRef]

17. Arias-Londoño, A.; Gil-González, W.; Montoya, O. A Linearized Approach for the Electric Light Commercial Vehicle Routing Problem Combined with Charging Station Siting and Power Distribution Network Assessment. Appl. Sci. 2021, 11, 4870. [CrossRef]

18. Deng, J.; Li, J.; Li, C.; Han, Y.; Liu, Q.; Niu, B.; Liu, L.; Zhang, B. A hybrid algorithm for electric vehicle routing problem with nonlinear charging. J. Intell. Fuzzy Syst. 2021, 40, 5383-5402. [CrossRef]

19. Schneider, F.; Thonemann, U.W.; Klabjan, D. Optimization of Battery Charging and Purchasing at Electric Vehicle Battery Swap Stations. Transp. Sci. 2018, 52, 1211-1234. [CrossRef]

20. Sun, B.; Sun, X.; Tsang, D.H.; Whitt, W. Optimal battery purchasing and charging strategy at electric vehicle battery swap stations. Eur. J. Oper. Res. 2019, 279, 524-539. [CrossRef]

21. Zhong, L.; Pei, M. Optimal Design for a Shared Swap Charging System Considering the Electric Vehicle Battery Charging Rate. Energies 2020, 13, 1213. [CrossRef] 
22. Upchurch, C.; Kuby, M. Comparing the p-median and flow-refueling models for locating alternative-fuel stations. J. Transp. Geogr. 2010, 18, 750-758. [CrossRef]

23. Shen, Z.-J.M.; Feng, B.; Mao, C.; Ran, L. Optimization models for electric vehicle service operations: A literature review. Transp. Res. Part B Methodol. 2019, 128, 462-477. [CrossRef]

24. Yang, J.; Sun, H. A hybrid genetic algorithm for battery swap stations location and inventory problem. Int. J. Shipp. Transp. Logist. 2015, 7, 246. [CrossRef]

25. An, K.; Jing, W.; Kim, I. Battery-swapping facility planning for electric buses with local charging systems. Int. J. Sustain. Transp. 2019, 14, 489-502. [CrossRef]

26. He, F.; Yin, Y.; Zhou, J. Deploying public charging stations for electric vehicles on urban road networks. Transp. Res. Part C Emerg. Technol. 2015, 60, 227-240. [CrossRef]

27. Zeng, M.; Pan, Y.; Zhang, D.; Lu, Z.; Li, Y. Data-Driven Location Selection for Battery Swapping Stations. IEEE Access 2019, 7, 133760-133771. [CrossRef]

28. Yang, X.; Shao, C.; Zhuge, C.; Sun, M.; Wang, P.; Wang, S. Deploying battery swap stations for shared electric vehicles using trajectory data. Transp. Res. Part D Transp. Environ. 2021, 97, 102943. [CrossRef]

29. Wang, R.; Li, X.; Xu, C.; Li, F. Study on location decision framework of electric vehicle battery swapping station: Using a hybrid MCDM method. Sustain. Cities Soc. 2020, 61, 102149. [CrossRef]

30. Yang, J.; Sun, H. Battery swap station location-routing problem with capacitated electric vehicles. Comput. Oper. Res. 2015, 55, 217-232. [CrossRef]

31. Hof, J.; Schneider, M.; Goeke, D. Solving the battery swap station location-routing problem with capacitated electric vehicles using an AVNS algorithm for vehicle-routing problems with intermediate stops. Transp. Res. Part B Methodol. 2017, 97, 102-112. [CrossRef]

32. Arango, J.D.S.; Londono, A.A.; Echeverri, M.G. Electric Vehicles for merchandise transportation: Integrated planning taking into acount the electrical distribution system. IEEE Lat. Am. Trans. 2018, 16, 2192-2198. [CrossRef]

33. Wang, D.; Zhou, H.; Feng, R. A two-echelon vehicle routing problem involving electric vehicles with time windows. J. Phys. Conf. Ser. 2019, 1324, 012071. [CrossRef]

34. Jie, W.; Yang, J.; Zhang, M.; Huang, Y. The two-echelon capacitated electric vehicle routing problem with battery swapping stations: Formulation and efficient methodology. Eur. J. Oper. Res. 2019, 272, 879-904. [CrossRef]

35. Ban, M.F.; Yu, J.L.; Yao, Y.Y. Joint Optimal Scheduling for Electric Vehicle Battery Swapping-charging Systems Based on Wind Farms. CSEE J. Power Energy Syst. 2021, 7, 555-566.

36. Zhou, B.-H.; Tan, F. Electric vehicle handling routing and battery swap station location optimisation for automotive assembly lines. Int. J. Comput. Integr. Manuf. 2018, 31, 978-991. [CrossRef]

37. Zhang, S.; Chen, M.Z.; Zhang, W.Y. A novel location-routing problem in electric vehicle transportation with stochastic de-mands. J. Clean. Prod. 2019, 221, 567-581. [CrossRef]

38. Li, J.; Wang, F.; He, Y. Electric Vehicle Routing Problem with Battery Swapping Considering Energy Consumption and Carbon Emissions. Sustainability 2020, 12, 10537. [CrossRef]

39. Mao, H.; Shi, J.; Zhou, Y.; Zhang, G. The Electric Vehicle Routing Problem With Time Windows and Multiple Recharging Options. IEEE Access 2020, 8, 114864-114875. [CrossRef]

40. Sun, B.; Tan, X.Q.; Tsang, D.H.K. Optimal Charging Operation of Battery Swapping Stations with QoS Guarantee. In Proceedings of the IEEE International Conference on Smart Grid Communications, Venice, Italy, 3-6 November 2014; pp. 13-18.

41. Tan, X.Q.; Sun, B.; Tsang, D.H.K. Queueing Network Models for Electric Vehicle Charging Station with Battery Swapping. In Proceedings of the IEEE International Conference on Smart Grid Communications, Venice, Italy, 3-6 November 2014; pp. 1-6.

42. Jing, W.T.; Kim, I.; An, K. The Uncapacitated Battery Swapping Facility Location Problem with Localized Charging System Serving Electric Bus Fleet. In Proceedings of the International Symposium of Transport Simulation, Matsuyama, Japan, 6-8 August 2018; pp. 227-234.

43. Lu, X.; Liu, N.; Huang, Y.; Zhang, J.; Zhou, N. Optimal Configuration of EV Battery Swapping Station Considering Service Availability. In Proceedings of the 1st International Conference on Intelligent Green Building and Smart Grid (IGBSG), Taipei, Taiwan, 23-25 April 2014; National Taiwan University of Science and Technology: Taipei, Taiwan, 2014.

44. Wu, T.H.; Pang, G.K.H.; Choy, K.; Lam, H. An optimization model for a battery swapping station in Hong Kong. In Proceedings of the IEEE Transportation Electrification Conference and Expo (ITEC), Dearborn, MI, USA, 14-17 June 2015. [CrossRef]

45. Liu, N.; Lin, X.; Chen, Q.; Zou, F.; Chen, P.Z. Optimal Configuration for Batteries and Chargers in Battery Switch Station Considering Extra Waiting Time of Electric Vehicles. J. Energy Eng. 2017, 143, 04016035. [CrossRef]

46. Tan, X.; Sun, B.; Wu, Y.; Tsang, D.H. Asymptotic performance evaluation of battery swapping and charging station for electric vehicles. Perform. Eval. 2018, 119, 43-57. [CrossRef]

47. Nie, Y.; Chung, C.Y.; Chen, L.; Wang, X.; Yu, R.; Qin, M. In Inventory Management of DSCC System via Improved (s, S) Model. In Proceedings of the IEEE PES General Meeting, National Harbor, MD, USA, 27-31 July 2014.

48. Dai, Q.; Cai, T.; Duan, S.; Zhang, W.; Zhao, J. A smart energy management system for electric city bus battery swap station. In Proceedings of the IEEE Transportation Electrification Conference and Expo, Dearborn, MI, USA, 15-18 June 2014. [CrossRef]

49. Wu, H.; Pang, G.K.H.; Choy, K.; Lam, H. A charging-scheme decision model for electric vehicle battery swapping station using varied population evolutionary algorithms. Appl. Soft Comput. 2017, 61, 905-920. [CrossRef] 
50. Amiri, S.S.; Jadid, S.; Saboori, H. Multi-objective optimum charging management of electric vehicles through battery swapping stations. Energy 2018, 165, 549-562. [CrossRef]

51. Huang, X.; Qiang, H.; Zhang, Q.; Li, H. Research on ISFLA-Based Optimal Control Strategy for the Coordinated Charging of EV Battery Swap Station. Math. Probl. Eng. 2013, 2013, 1-7. [CrossRef]

52. Zhao, G.; Guo, J.; Qiang, H. Research on SFLA-Based Bidirectional Coordinated Control Strategy for EV Battery Swapping Station. CMC Comput. Mater. Continua 2017, 53, 343-356.

53. Gao, T.; Liu, R.Y.; Hua, K. Dispatching Strategy Optimization for Orderly Charging and Discharging of Flectric Vehicle Battery Charging and Swapping Station. In Proceedings of the 5th International Conference on Electric Utility Deregulation and Restructuring and Power Technologies (DRPT), Changsha, China, 26-29 November 2015; pp. 2640-2645.

54. Rao, R.; Zhang, X.; Xie, J.; Ju, L. Optimizing electric vehicle users' charging behavior in battery swapping mode. Appl. Energy 2015, 155, 547-559. [CrossRef]

55. Gao, Y.; Yang, J.J.; Yang, M.; Li, Z. Deep Reinforcement Learning Based Optimal Schedule for a Battery Swapping Station Considering Uncertainties. IEEE Trans. Ind. Appl. 2020, 56, 5775-5784. [CrossRef]

56. Sun, B.; Tan, X.Q.; Tsang, D.H.K. Optimal Charging Operation of Battery Swapping and Charging Stations with QoS Guarantee. IEEE Trans. Smart Grid 2018, 9, 4689-4701. [CrossRef]

57. Widrick, R.S.; Nurre, S.G.; Robbins, M. Optimal Policies for the Management of an Electric Vehicle Battery Swap Station. Transp. Sci. 2018, 52, 59-79. [CrossRef]

58. Asadi, A.; Pinkley, S.N. A stochastic scheduling, allocation, and inventory replenishment problem for battery swap stations. Transp. Res. Part E Logist. Transp. Rev. 2021, 146, 1366-5545. [CrossRef]

59. Zhang, M.; Wen, K.; Zhou, C.; Li, W.; Zou, N. Capacity Optimization Configuration for Second Use of Electric Vehicle Batteries in Battery Swapping Stations. In Proceedings of the 2nd IEEE International Conference on Civil Aviation Safety and Information Technology (ICCASIT), Wuhan, China, 14-16 October 2020; pp. 282-288.

60. Zhang, M.; Chen, J. The Energy Management and Optimized Operation of Electric Vehicles Based on Microgrid. IEEE Trans. Power Deliv. 2014, 29, 1427-1435. [CrossRef]

61. Rehman, U.; Feng, D.; Su, H.; Numan, M.; Abbas, F. Network overloading management by exploiting the in-system batteries of electric vehicles. Int. J. Energy Res. 2021, 45, 5866-5880. [CrossRef]

62. Sepetanc, K.; Pandzic, H. A Cluster-based Operation Model of Aggregated Battery Swapping Stations. IEEE Trans. Power Syst. 2020, 35, 249-260. [CrossRef]

63. Liang, Y.; Zhang, X.; Xie, J.; Liu, W. An Optimal Operation Model and Ordered Charging/Discharging Strategy for Battery Swapping Stations. Sustainability 2017, 9, 700. [CrossRef]

64. Schiffer, M.; Schneider, M.; Walther, G.; Laporte, G. Vehicle Routing and Location Routing with Intermediate Stops: A Review. Transp. Sci. 2019, 53, 319-343. [CrossRef]

65. Kucukoglu, I.; Dewil, R.; Cattrysse, D. The electric vehicle routing problem and its variations: A literature review. Comput. Ind. Eng. 2021, 161, 107650. [CrossRef]

66. You, P.; Low, S.H.; Yang, Z.; Zhang, Y.; Fu, L. Real-time recommendation algorithm of battery swapping stations for electric taxis. In Proceedings of the 2016 IEEE Power and Energy Society General Meeting (PESGM), Boston, MA, USA, 17-21 July 2016; pp. 1-5. [CrossRef]

67. You, P.; Pang, J.Z.F.; Chen, M.; Low, S.H.; Sun, Y. Battery swapping assignment for electric vehicles: A bipartite matching approach. In Proceedings of the 2017 IEEE 56th Annual Conference on Decision and Control (CDC), Melbourne, Australia, 12-15 December 2017; pp. 1421-1426. [CrossRef]

68. You, P.; Cheng, P.; Pang, J.Z.; Low, S.H. Efficient Online Station Assignment for EV Battery Swapping. In Proceedings of the Ninth International Conference on Future Energy Systems, Karlsruhe, Germany, 12-15 June 2018; pp. 383-385. [CrossRef]

69. You, P.; Low, S.H.; Tushar, W.; Geng, G.; Yuen, C.; Yang, Z.; Sun, Y. Scheduling of EV Battery Swapping—Part I: Centralized Solution. IEEE Trans. Control Netw. Syst. 2018, 5, 1887-1897. [CrossRef]

70. You, P.; Low, S.H.; Zhang, L.; Deng, R.; Giannakis, G.B.; Sun, Y.; Yang, Z. Scheduling of EV Battery Swapping-Part II: Distributed Solutions. IEEE Trans. Control Netw. Syst. 2018, 5, 1920-1930. [CrossRef]

71. Choi, D.I.; Lim, D.-E. Analysis of the State-Dependent Queueing Model and Its Application to Battery Swapping and Charging Stations. Sustainability 2020, 12, 2343. [CrossRef]

72. Shu, X.; Li, G.; Zhang, Y.; Shen, S.; Chen, Z.; Liu, Y. Stage of Charge Estimation of Lithium-Ion Battery Packs Based on Improved Cubature Kalman Filter With Long Short-Term Memory Model. IEEE Trans. Transp. Electrif. 2021, 7, 1271-1284. [CrossRef]

73. Roselyn, J.P.; Ravi, A.; Devaraj, D.; Venkatesan, R. Optimal SoC Estimation Considering Hysteresis Effect for Effective Battery Management in Shipboard Batteries. IEEE J. Emerg. Sel. Top. Power Electron. 2021, 9, 5533-5541. [CrossRef]

74. Zhou, W.; Zheng, Y.; Pan, Z.; Lu, Q. Review on the Battery Model and SOC Estimation Method. Processes 2021, 9, 1685. [CrossRef]

75. Naguib, M.; Kollmeyer, P.; Emadi, A. Lithium-Ion Battery Pack Robust State of Charge Estimation, Cell Inconsistency, and Balancing: Review. IEEE Access 2021, 9, 50570-50582. [CrossRef]

76. Espedal, I.B.; Jinasena, A.; Burheim, O.S.; Lamb, J.J. Current Trends for State-of-Charge (SoC) Estimation in Lithium-Ion Battery Electric Vehicles. Energies 2021, 14, 3284. [CrossRef]

77. Deleebeeck, L.; Veltze, S. Electrochemical impedance spectroscopy study of commercial Li-ion phosphate batteries: A me-trology perspective. Int. J. Energy Res. 2020, 44, 7158-7182. [CrossRef] 
78. Ban, M.; Zhang, Z.; Li, C.; Li, Z.; Liu, Y. Optimal scheduling for electric vehicle battery swapping-charging system based on nanogrids. Int. J. Electr. Power Energy Syst. 2021, 130, 106967. [CrossRef]

79. Wang, R.; Li, X.; Li, C. Optimal selection of sustainable battery supplier for battery swapping station based on Triangular fuzzy entropy-MULTIMOORA method. J. Energy Storage 2021, 34, 102013. [CrossRef]

80. Zhang, M.; Li, W.; Yu, S.S.; Wen, K.; Zhou, C.; Shi, P. A unified configurational optimization framework for battery swapping and charging stations considering electric vehicle uncertainty. Energy 2021, 218, 119536. [CrossRef] 